\title{
Transformasi Makna dan Fungsi Ruang di RPTRA Kalijodo dalam Pergulatan Citra Kota Jakarta
}

\author{
Eka Permanasari dan Thomas Lientino
}

Universitas Pembangunan Jaya

Eka.permanasari@upj.ac.id

\begin{abstract}
ABSTRAK
Wilayah Kalijodo yang terletak di Kelurahan Angke fungsi awalnya adalah Ruang Terbuka Hijau namun selalu dipenuhi oleh bedeng liar dan bangunan semi permanen. Kalijodo memiliki sejarah panjang sebagai wilayah yang terkait perjudian, perdagangan manusia, pelacuran dan wilayah hiburan ilegal. Sebagai kelanjutan program pembangunan pilot project RPTRA di 6 wilayah di Jakarta, Gubernur Ahok lalu membangun Ruang Publik Terpadu Ramah Anak di kawasan yang kontroversial ini. Menggandeng Arsitek Yori Antar, kawasan Kalijodo disulap menjadi ruang publik yang baru dan menarik minat masyarakat untuk mengunjunginya. Melalui mural Public Art dan skatepark, RPTRA kalijodo menjadi pusat kegiatan dan wisata baru di tengah kota Jakarta. Preman, wanita tuna susila dan germo tersingkir, sebagian pulang kampung dan sebagian membangun bedeng sementara di bawah jembatan tol. Geliat bisnis haram masih ada meskipun dalam status dormant. Namun eforia turunnya Ahok pasca kasus penistaan agama begitu pesat sehingga dalam waktu satu hari kawasan parkiran di RPTRA Kalijodo menjadi semrawut, mesin parkir dirusak dan geliat bisnis ilegal kembali berdenyut. Layer makna dan fungsi ruang di RPTRA Kalijodo berganti begitu cepat dan mempengaruhi citra kota. Melalui metode observasi, wawancara dan studi literatur, tulisan ini mengulik pergulatan citra kota dengan menganalisis relasi kontestasi keinginan pemerintah dan pengguna keseharian.
\end{abstract}

Kata kunci: Perencanaan, ruang publik, citra kota, Jakarta.

\section{ABSTRACT}

Kalijodo has a long history in terms of gambling, prostitution, human trafficking and other illicit activities. Although it is a green belt area, the location had always being filled with semipermanent buildings. The area was changed its meaning in 2016 when the late Governor of Ahok with the help of the police and army, eradicated these housing and transformed this place as the community center (RPTRA-Ruang Publik Terpadu Ramah Anak). Together with Yori Antar, Basuki changed Kalijodo into a new center for Jakarta with its mural and skatepark. Former illicit users have been pushed out from the site. Some built a temporary shelter under the highway bridge while others went to their villages. After the fall of Basuki due to the blasphemy crime, the image of RPTRA Kalijodo was contested. Within a day, the area was filled with illegal parking and prostitution returned in different forms taking place under the highway bridge. Layers of meaning and use of Kalijodo transforms rapidly and in results changes the image of the city. Through observation, interviews and archival research, this paper analyses the contestation of the city image by investigating the relationship between the top-down approach and the everyday life uses of space.

Keywords: city planning, public space, city image, Jakarta. 


\section{Pendahuluan}

Kawasan Kalijodo memiliki sejarah panjang dari awal mula pembentukannya. Nama Kalijodo sendiri sebenarnya bukan merupakan nama dari suatu daerah tertentu. Pada novel Ca-Bau-Kan, yang ditulis oleh Remy Syalado, istilah Kalijodo ini bermula dari adanya pedagang - pedagang keturunan Tionghoa yang datang ke bantaran sungai kali Angke untuk melakukan tradisi Peh-Cun, yaitu bernyanyi dan berpantun di atas perahu perahu yang telah dihiasi (Silado, 1999). Pada tradisi ini perahu yang dihiasi tersebut akan ada perahu yang diisi oleh laki-laki dan ada perahu yang diisi perempuan. Jika kemudian laki-laki dan perempuan yang berada dalam perahu berbeda tersebut saling tertarik, maka baik laki-laki dan perempuan akan saling melemparkan sebuah kue yang terbuat dari terigu dan kacang yang dilapisi daun bernama Bak Cang (Saidi, 2016) (Tionghoa, 2015).

I Ketut Suardana dalam tesisnya tentang "Asal Mula Pelacuran Kalijodo", menuliskan bahwa pada awalnya berada di lokasi yang kini menjadi tol Tomang - Pluit, sudah terdapat tenda atau warung - warung yang di lengkapi oleh para wanita penghibur yang berasal dari berbagai daerah di Indonesia. Lambat laun praktek pelacuran di tempat tersebut terus berkembang, sehingga dalam rentang waktu sampai tahun 1988, bukan lagi tenda yang didirikan pada kawasan Kalijodo lama ini namun menjadi bangunan permanen liar berupa rumah tinggal yang berjumlah 102 unit (Suardana, 2000). Pada tahun 1992, wilayah pelacuran dibongkar untuk dialihfungsikan sebagai tol TomangPluit. Beberapa warga yang terkena penggusuran ini ada yang kembali ke kampung halamannya, tetapi untuk para germo yang memiliki modal, memilih pindah ke Kampung Kebon Pisang (lokasi Kalijodo saat ini) yang hanya berjarak 70 meter dari lokasi yang lama (Suardana, 2000). Lokasi inilah yang akhirnya menjadi wilayah prostitusi yang terkenal di Kalijodo.

Sayangnya, lahan yang dijadikan prostitusi ini merupakan salah satu wilayah yang semestinya menjadi Ruang Terbuka Hijau di Jakarta. Berdasarkan data detail tata ruang Jakarta pada 2011, RTH di Jakarta Utara seluas 2.901,24 hektar Meskipun demikian, jumlah RTH ini hanya $10 \%$ dari total wilayah DKI Jakarta. Luas itu masih jauh dari RTH yang ditargetkan yaitu sebesar 30\% (5.438 hektar). Untuk luas total wilayah Kalijodo sekitar empat hektar. (Putera, 2016).

Minimnya ruang terbuka hijau juga diperparah dengan kondisi lahan sebagian RTH di Jakarta yang tidak semuanya dalam kondisi baik. Taman-taman kota serta taman lingkungan sebagian sudah diambil alih oleh warga maupun oknum sebagai informal settlements, lahan parkir, maupun usaha bisnis lainnya. Menyadari hal tersebut, Gubernur DKI periode Basuki Tjahaja Purnama membuat terobosan untuk mengembalikan fungsi lahan-lahan tersebut sebagai RTH. Sejalan dengan kelanjutan program pilot project Ruang Publik Terpadu Ramah Anak (RPTRA) Tahap 1 di 6 wilayah (Permanasari, Nurhidayah, \& Nugraha, 2018), Basuki memerintahkan untuk membangun 61 RPTRA dengan menggandeng CSR dari berbagai perusahaan, termasuk salah satunnya adalah Sinarmas Land (Aziza, 2017).

Meskipun demikian, pembangunan RPTRA di Kalijodo ini tidak terlepas dari kontroversi. Pembersihan lahan berlangsung selama tiga hari dengan bantuan aparat gabungan dari TNI, Polri dan satpol PP (Syurkani, 2016). Sebagian warga pindah dari lokasi ke rusun yang disediakan, sebagian lainnya kembali ke kampung halaman dan sisanya bertahan di bedeng-bedeng di bawah jembatan. Kecaman tentang proses pembersihan RPTRA lebih ke arah memisahkan dari warga yang tinggal disana dengan lingkungan hidupnya. Banyak yang melihat proses tersebut sebagai tindakan tak manusiawi. Kontroversi juga menyoroti langkah pemerintah yang ingin menambah jumlah RTH di Jakarta dengan menggusur pemukiman di bantaran sungai di Kalijodo. 
Menurut Supriyatna, penambahan RTH bisa mengandalkan kontribusi 20\% RTH dari total lahan yang dibangun oleh developer (Putera, 2016). Namun dengan kondisi wilayah Jakarta tidak banyak yang tersisa untuk lahan pemukiman, tentu saja pendapat ini menjadi polemik tersendiri. Paper ini mengulas bagaimana kawasan Kalijodo berubah dari yang awalnya lokasi pelacuran hingga menjadi Ruang Publik Terpadu Ramah Anak pada zaman pemerintahan. Melalui studi literatur, observasi dan wawancara, penulis melihat transformasi makna dan ruang di wilayah Kalijodo pasca dibangunnya RPTRA.

\section{Kajian Teori dan Metode \\ 2.1 Kajian Teori}

Dengan dibersihkannya wilayah Kalijodo, harapannya bantaran sungai menjadi bersih dan kembali berfungsi sebagai Ruang Terbuka Hijau. Citra Kota Jakarta berubah seiring dengan pembersihan yang kontroversial. Prinsip urban planning sendiri menurut Friedman (Friedman, 2002) sangatlah 'utopian', dalam artian kita selalu menginginkan sebuah kota yang ideal yang memenuhi impian manusia. Oleh karenanya, meski pola pikir utopian terkesan mengejar mimpi, ia secara intrinsik memiliki unsur kritik dan visi yang membangun. Namun menurut Friedman, pola pikir utopian semestinya menghindari dongeng (fairy tales), dan fokus pada masa depan kota yang lebih baik dengan keterliatan koalisi politik antara pemerintah dan masayarakat (Friedman, 2002).

Ide Friedman senada dengan ungkapan Boyer (1994) yang mengatakan bahwa perencanaan sebuah kota dan proyek arsitekturalnya, selalu memiliki pola pikir utopian yaitu masyarakat akan menjadi lebih baik menuju masa depannya (Boyer, 1994). Keinginan untuk memberikan mimpi terbaik bagi masyarakat seringkali digunakan oleh penguasa dalam merencanakan sebuah kota, salah satunya adalah ruang publik. Vale (1992) dalam bukunya Architecture, Power and National Identity membahas tentang muatan politis dalam perencanaan sebuah kota maupun bangunan arsitektural yang nantinya berimbas pada identitas sebuah bangsa. Perencanaan kota yang seringkali dijadikan sebagai landasan meningkatkan rasa nasionalisme ini seringkali terletak di ibukota negara (Capitol). Maka tidaklah heran jika ibu kota negara saling berlomba menunjukkan sisi rancangan terbaiknya yang terlihat dari masterplan maupun bangunan arsitekturalnya (Vale, 1992).

Ketika sebuah pemerintahan berakhir, maka pada umumnya pemerintahan selanjutnya akan menciptakan sebuah identitas politik yang tertuang dalam bentuk arsitektural maupun perencanaan kota yang berbeda dari rezim sebelumnya (Kusno, 2000). Uniknya, setiap rezim memiliki cara sendiri dalam penyampaian bahasa politik dalam ruang. Bahkan tak jarang, keputusan pengubahan sebuah kota bukan terletak pada presiden, melainkan Gubernur. Sebagai contoh, pada zaman pasca reformasi, Gubernur Sutiyoso melakukan pemagaran di Taman Medan Merdeka sebagai bentuk intervensi sosial yang melarang demonstran, wanita tuna susila dan gelandangan memasuki wilayah Monumen Nasional yang menyiratkan identitas nasional. Selain itu ia juga merenovasi Bundaran HI dan memperbaiki air mancur di Monas untuk meningkatkan rasa nasionalisme.

Jika pada tahun 2000an saat Sutiyoso masih menjabat sebagai Gubernur lebih memusatkan pendekatannya pada ruang publik yang meningkatkan rasa nasionalisme, pada era tahun 2012, Gubernur Fauzi Bowo ia memusatkan perhatiannya pada pembangunan tanggul laut (Giant Sea Wall, sebagai cerminan 'Capitol' baru serta menyelamatkan Jakarta agar tidak tenggelam (Permanasari, 2014). Pada pertengahan tahun 2014, Gubernur Basuki Tjahaja Purnama bersama Ketua Tim Penggerak PKK, meluncurkan program menciptakan Ruang Publik Terpadu ramah Anak. Berawal dengan 6 pilot project RPTRA Tahap I, Pemprov DKI menggandeng CSR dari berbagai perusahaan membangun 61 RPTRA Tahap II. Proyek ini merupakan ambisi Basuki Tjahaja Purnama 
untuk menciptakan 200 ruang interaksi bagi masyarakat dan bagian dari strategi untuk menambah jumlah RTH di Jakarta. Salah satu RPTRA yang dibangun pada tahap II adalah RPTRA Kalijodo.

Dengan demikian sebuah kota menjadi wadah dari berbagai lapisan makna dan citra ruang yang bertumpuk. Rossi (1986) menekankan bahwa citra sebuah kota sangat bergantung pada daya ingatan seseorang akan kota tersebut. Sebuah kota merekam setiap kejadian lampau dan kejadian baru akan memberikan nuansa dan citra baru kota (Rossi, 1986). Kejadian-kejadian dalam kota bisa terjadi karena adanya ruang publik yang memberikan ruang interaksi. Menurut Jan Gehl (1987) dalam bukunya Life Between Buildings, orang selalu tertarik untuk melakukan kontak dengan orang lain melalui berbagai cara. Misalnya, orang akan lebih tertarik duduk pada tempat duduk yang menghadap ke kerumunan aktifitas orang lain dibanding pada tempat duduk yang hanya memiliki pandangan tanpa aktifitas manusia (Gehl, 1987).

RPTRA merupakan sebuah wadah yang memberikan kesempatan orang untuk bertemu dan berinteraksi melalui aktifitas mereka. Pemerintah Provinsi DKI Jakarta menginginkan agar RPTRA bukan hanya sekedar pemenuhan kriteria ruang hijau saja, melainkan juga sebagai ruang yang memberikan kesempatan interaksi manusia dari semua golongan umur. Meski demikian, pembuatan RPTRA ini juga banyak yang menyangsikan, baik dari sisi pendanaannya maupun mekanisme pembangunannya yang berusaha melibatkan masyawakat sekitar RPTRA.

Sebagai lanjutan dari RPTRA Tahap I, maka pembangunan RPTRA Kalijodo merupakan bagian dari pembangunan RPTRA Tahap II. Dengan menggandeng SinarmasLand, Pemprov DKI bersama-sama dengan Tim Penggerak PKK Provinsi DKI Jakarta membangun kawasan eks Kalijodo menjadi wilayah RPTRA baru. Tim ini sepakat untuk meminta bantuan Yori Antar sebagai arsitek yang dapat mengembangkan kawasan Kalijodo berdasarkan desain awal yang sudah ditetapkan oleh tim arsitek dari Arkonin yang diketuai oleh Ir. Achmad Noerzaman dan panduan konsep ruang publik yang dipimpin oleh Urban Designer penulis utama dan panduan pelibatan masyarakat oleh Imam Prasodjo dari Universitas Indonesia.

Kalijodo dipilih sebagai studi kasus karena di antara RPTRA yang lain, Kalijodo memiliki keunikan sejarah, identitas dan menjadi ajang pertarungan kepentingan baik di level pemerintah maupun level masyarakat. Lahan yang awalnya milik pemprov DKI ini sudah bertahun-tahun dikuasai oleh warga dan sebagian besar dijadikan sebagai lokalisasi pelacuran, parkir liar serta pemukiman tak bersurat (illegal settlements). Premanisme, pelacuran dan perjudian menjadi pemandangan keseharian di Kalijodo (Murti, 2004). Ketika RPTRA dibangun dilokasi ini maka bukan hanya pertentangan yang dilakukan oleh elite politik yang memiliki ragam kepentingan, namun juga dari para mafia pemilik rumah karaoke dan bridal yang merasa dirugikan. Selain itu ada juga dari pihak masyarakat maupun para penghuni lokalisasi yang merasa keberatan wilayah mereka digusur. RPTRA Kalijodo merupakan RPTRA yang menjadi salah satu contoh bagaimana kontestasi politik dalam ruang urban diperlihatkan.

Meskipun diawal direncanakan agar RPTRA Kalijodo ini berhasil sebagai ruang publik, untuk menganalisis keberhasilan sebuah ruang publik, maka ada beberapa kriteria yang harus dimiliki sebuah ruang publik. Dalam jurnal Landscape Architecture, Francis (1998) membeberkan beberapa kriteria kesuksesan ruang publik, diantaranya keberagaman pengguna, tingkat kenyamanan, terakses oleh siapapun, memberikan makna ruang dan meningkatkan kualitas ekologi (Francis, 1998). Kriteria keberagaman pengguna dan terakses siapapun ditunjukkan oleh semakin terbukanya ruang publik bagi segala usia, kelompok dan golongan maka ia mencerminkan kesetaraan akses penggunaan ruang. Sementara itu tingkat kenyamanan ditentukan oleh tersedianya fasilitas seperti bangku, naungan bagi pengguna maupun fasilitas pendukung lainnya 
yang membuat pengunjung merasa nyaman. Kunci kesuksesan dengan indikator kenyamanan adalah seberapa lama orang akan menghabiskan waktu di ruang publik. Untuk faktor peningkatan kualitas ekologi maka dengan adanya ruang terbuka memberikan kesempatan bagi manusia berinteraksi dengan alam. Ruang publik menjadi sebuah wadah interaksi manusia, memiliki makna dan simbol dari keberagaman pengguna.

Dengan kriteria tersebut, ruang publik bukan hanya sekedar terbuka untuk umum namun dapat berfungsi sebagai identitas sebuah kota. Jika Friedmand (2002) dan Boyer (1994) membahas bagaimana sebuah kota diciptakan berdasarkan utopian thinking, maka kunci keberhasilannya diukur dari bagaimana masyarakat menggunakan ruang publik tersebut dalam keseharian (Boyer, 1994) (Friedman, 2002). Oleh karenanya tulisan bertujuan mengulas bagaimana pemerintah menciptakan ruang publik sebagai citra kota yang baru dan bagaimana makna serta fungsi ruang tersebut bertransformasi.

\subsection{Metode Penelitian}

Penelitian ini menggunakan pedekatan metode kualitatif untuk mengetahui bagaimana transformasi makna dan identitas ruang kota terjadi di RPTRA Kalijodo sebelum dibangun hingga pasca lengsernya mantan Gubernur Basuki Tjahaja Purnama. Sementara itu, untuk melihat sejauh mana RPTRA Kalijodo ini bermanfaat dan dugunakan oleh warga Jakarta, maka peneliti menggunakan metode kuantitatif dalam melihat jumlah pengunjung pada saat hari kerja dan akhir pecan di tiga waktu berbeda (pagi, siang dan sore). Untuk itu ada beberapa teknik pengumpulan data yang dilakukan: Sumber data primer berasal dari hasil observasi langsung dan wawancara, sedangkan data sekunder akan didapatkan melalui studi literatur.

Observasi bertujuan untuk mengetahui bagaimana RPTRA digunakan dalam keseharian. Observasi dilakukan pada waktu yang berbeda untuk mengetahui pengguna ruang, jumlah orang, lokasi favorit berkegiatan pada ruang, serta kapan ruang tersebut digunakan. Observasi ini dilakukan dengan mengambil beberapa waktu berbeda untuk mendapatkan gambaran menyeluruh mengenai pemanfaatan ruang publik. Observasi dilakukan pada hari kerja dan hari libur di saat pagi, siang dan sore hari. Jangka waktu pengamatan adalah 1 bulan di bulan April 2017 untuk mendapatkan gambaran langsung kegiatan yang terjadi pada RPTRA Kalijodo pasca peresmian dan pemilihan Gubernur periode 2017-2021. Peneliti melihat pergulatan sosial yang terjadi di wilayah RPTRA Kalijodo, antara keinginan pemerintah akan ruang publik yang ideal dengan kondisi di lapangan yang masih sarat akan kebiasaan lama kegiatan Kalijodo.

Wawancara dilakukan dengan bantuan semi structured, yaitu pemberian kuesioner yang berisikan pertanyaan tertutup dan pertanyaan terbuka. Hal ini dilakukan untuk mendapatkan gambaran obyektif tentang keberagaman pengguna, pengalaman ruang, interpretasi pengunjung tentang RPTRA Kalijodo pasca peresmian dan pasca berganti kepemimpinan. Wawancara dilakukan kepada beberapa narasumber: Pengunjung RPTRA Kalijodo (anak 7-10 tahun, remaja 11-17 tahun, dewasa), Pedagang yang berjualan di RPTRA Kalijodo, Pengurus RPTRA Kalijodo. Total responden anak-anak adalah 50 orang, remaja 50 orang, dewasa 50 orang dan pedagang serta pengurus RPTRA Kalijodo sebanyak 30 orang. Kuesioner diberikan dengan jenis pertanyaan antara lain: apa tujuan pengunjung ke RPTRA Kalijodo, apa peran RPTRA Kalijodo, fasilitas apa yang mereka rasakan paling bermanfaat di RPTRA Kalijodo serta apa pendapat mereka tentang citra Kalijodo saat ini. Dengan menginterview beberapa narasumber ini diharapkan mendapatkan gambaran sepenuhnya mengenai transformasi makna ruang dari beragam pengguna.

Studi literatur digunakan untuk mencari latar belakang sejarah penggunaan ruang di wilayah RPTRA Kalijodo sebelum dibangunnya RPTRA, sejarah pembangunan RPTRA 
Kalijodo serta penggunaan ruang saat ini dari berbagai sumber media terkini. Data hasil studi literatur akan menjadi data pendukung yang melengkapi data hasil penelitian. Spesifiknya seperti kegiatan - kegiatan tertentu yang tidak didapat selama melakukan observasi dan wawancara. Data tersebut dapat dari berbagai sumber mulai dari koran, website, jurnal, tesis, dan buku.

\section{Hasil dan Diskusi}

Untuk memahami transformasi makna dan fungsi RPTRA Kalijodo, maka penulis akan mengulas 3 hal: proses pembentukan RPTRA Kalijodo, penggunaan RPTRA dalam keseharian dan kegiatan di RPTRA yang berlangsung pasca lengsernya Ahok.

\subsection{Proses Pembangunan dan Desain RPTRA}

Proses pembangunan RPTRA Kalijodo pada awalnya menemui kendala. Banyak yang menentang wilayah ini digusur dan dibangun ruang publik dengan alasan penggusuran menghilangkan kelekatan penghuni terhadap tempat yang mereka tinggali selama puluhan tahun (Yuliawati, 2016). Bahkan, pengusaha Daeng Aziz dan warga di Kalijodo berargumen bahwa prostitusi merupakan bagian dari kehidupan kota yang tidak dapat dipungkiri, sehingga keberadaannya tidak perlu digusur (Yuliawati, 2016). Wilayah Kalijodo ini sangat akrab dengan pub dan cafe tak berizin.

Terlepas dari upaya penolakan yang sifatnya demonstrasi maupun pelaporan ke Komnas HAM, Ahok tetap berupaya membersihkan wilayah Kalijodo. Menurut Ahok, ia membersihkan Kalijodo bukan karena kegiatan prostitusinya, melainkan pemukiman di wilayah tersebut menduduki wilayah jalur hijau (Sumantri, 2016). Pengembalian fungsi jalur hijau menjadi penting mengingat Jakarta membutuhkan RTH yang lebih tinggi, dan pemukiman di jalur hijau menyalahi aturan.

Proses penggusuran dilakukan secara bertahap. Pemprov DKI melalui Walikota Jakarta Utara Rustam Effendi memberikan peringatan tertulis kepada warga agar meninggalkan rumah nya terkait pengembalian fungsi RTH di wilayah Kalijodo. Peringatan ini dilanjutkan dengan pemberian Surat Peringatan 1 (SP1) dari Gubernur untuk warga membongkar sendiri huniannya dalam jangka waktu 11 hari sebelum penggusuran (Pratama, 2016). Surat Pemberitahuan 1 ini akan diikuti oleh SP2 pada H-7 dan SP3 pada H-3 sebelum pembongkaran (Pratama, 2016).

Sebagian warga yang tidak memiliki KTP diminta pulang kampung, dan bagi mereka yang ber KTP Jakarta dan sudah berkeluarga direlokasi ke Rusunawa Marunda di Jakarta Utara dan Rusunawa Pulogebang di Jakarta Timur (Ardiahanni, 2016). Bagi warga yang belum berkeluarga direlokasi ke Rusunawa Rawa Bebek di Jakarta Timur (Cahya, 2016).

Dengan berbekal surat peringatan kepada warga, pada tanggal 29 februari 2016, berkoordinasi dengan aparat gabungan TNI dan Polri, Ahok membersihkan lahan di Kalijodo. Bangunan pertama yang dibonglar adalah Kafe Intan milik Daeng Azis yang berdiri kokoh tiga lantai di atas lahan seluas $300 \mathrm{~m}^{2}$. Kafe ini terlihat mencolok dan megah ditengah-tengah kafe lain yang terbuat dari material semi permanen. Setelah wilayah ini bersih dari pemukiman liar, Ahok kemudian membangun RPTRA di wilayah ini.

Pembangunan RPTRA Kalijodo sebagai lanjutan dari 6 RPTRA menerapkan prinsip dan guidelines yang sudah ditentukan berdasarkan pembangunan RPTRA Tahap I. Untuk desainnya, Veronika Ahok meminta bantuan arsitek Yori Antar dan Tan Tik Lam untuk mengembangkan konsep desain yang menarik tanpa melanggar guidelines yang sudah ditetapkan. Yori kemudian mengembangkan desain bangunan RPTRA Kalijodo sementara Tan Tik Lam mengembangkan skate park di taman Kalijodo. 
Ditangan Yori Antar, kawasan Kalijodo berubah dari citra sebuah kawasan dengan hiburan malam, menjadi Ruang Publik Terpadu Ramah Anak. Wilayah Kalijodo sebagian besar berada di Jakarta Utara seluas 3.4 Ha dan sebagian kecil seluas $5.489 \mathrm{~m}^{2}$ berada di Jakarta Barat. Kawasan ini seolah dibelah oleh satu bangunan yang berfungsi pengolahan air.

Melalui rancangannya, Yori mengubah citra RPTRA sebagai ruang publik kebanyakan yang dibangun oleh pemerintah. Meskipun site Kalijodo memanjang, Yori menggunakan desain geometri segitiga untuk membagi wilayah. Geometri ini yang menjadi ciri khas dalam rancangan ruang di RPTRA. Untuk wilayah yang terletak di Jakarta Utara seluas 3.4 Ha, difungsikan sebagai RTH yang terdiri atas hutan kota dan aktifitas. Untuk wilayah hutan kota dibangunlah area jogging track, jalur sepeda dan penghijauan. Untuk wilayah aktifitas, dibangun skate park, amphiteatre dan function area (pavilion). Disisi lain, untuk wilayah yang terletak di Jakarta Barat seluas $5.489 \mathrm{~m}^{2}$, difungsikan sebagai bangunan RPTRA, lapangan futsal, kolam gizi, jalur refleksi dan bangunan RPTRA. Di dalam banguna RPTRA ini ada ruang untuk laktasi, kantor pengelola, perpustakaan, dan ruang serbaguna.

Kedua area ini dibatasi dengan dinding pembatas mural yang memisahkan kedua area RPTRA tersebut. Karena terletak di dua wilayah yang berbeda, maka kepengurusan RPTRA dan RTH juga menjadi berbeda, sesuai dengan wilayah administratif yang didudukinya. Meski begitu kedua area RPTRA tersebut tetap terbuka bagi semua masyarakat dan masing - masing area tersebut memiliki perbedaan fasilitas yang saling melengkapi satu sama lain (Gambar 1).

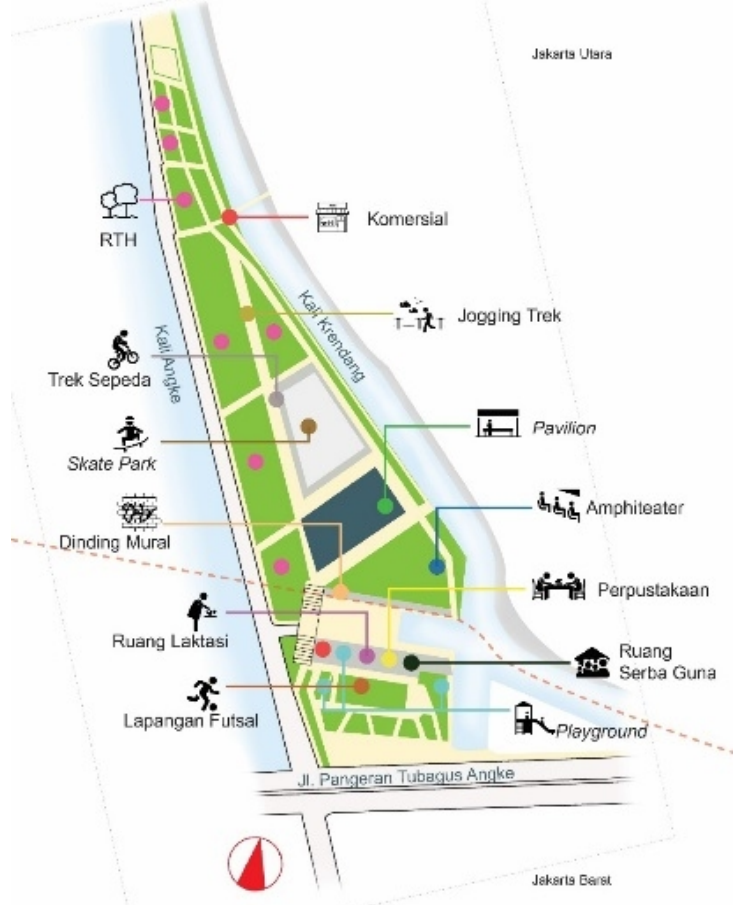

Gambar 1: Pembagian wilayah RPTRA dan RTH

Meskipun bangunan utama RPTRA hanya berbentuk kotak karena mengikuti panduan, namun memiliki background sebuah dinding besar berbentuk trapesium yang berfungsi seolah-olah sebagai prasasti. Lahan Kalijodo agak sedikit terpisahkan dengan lahan yang berada dibelakang bangunan utama, kesatuan bangunan terkoneksi dengan adanya tangga jembatan yang menghubungkan bangunan utama dan lapangan futsal dengan amphiteatre dan paviliun terbuka yang memiliki naungan. 
Seperti RPTRA yang lain, pembangunan RPTRA Kalijodo juga melibatkan masyarakat umum. Bahkan untuk menghias muralnya, Yori Antar bekerja sama dengan komunitas mural Indonesia untuk menorehkan masterpiece mereka pada dinding yang menghadap amphiteathre. Public Art didisplay sebagai bagian dari partisipasi masyarakat dalam ruang publik. (Gambar 2) Keunikan lain dari desain RPTRA Kalijodo adalah adanya skate park yang luas dengan bentuk unik turun naik sehingga mengundang para penggiat skateboard, sepeda BMX maupun orang umum mengunjungi wilayah ini.

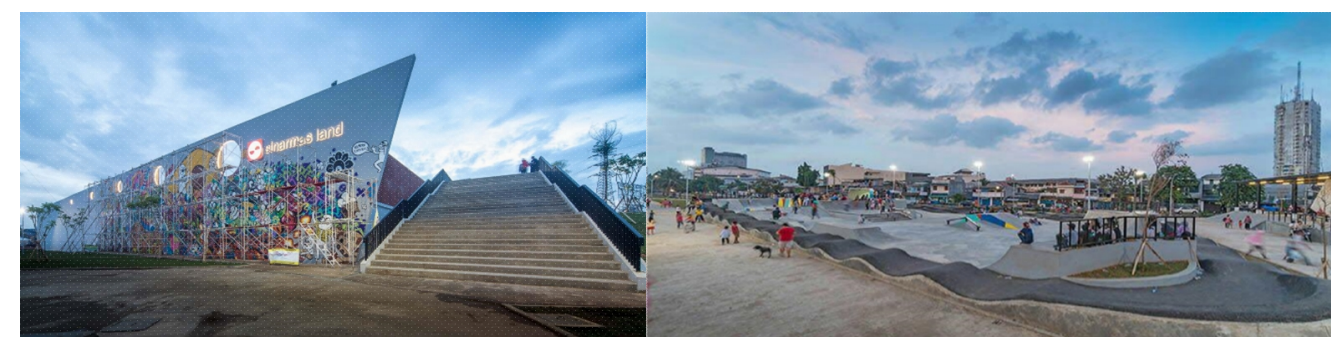

Gambar 2: Mural dan Skate Park di Kalijodo Sumber: Yori Antar, 2017

\section{2. $\quad$ Analisisis kriteria ruang publik yang baik}

Untuk menganalisis bagaimana RPTRA digunakan dalam keseharian sebagai ruang publik yang baik, maka observasi dilakukan untuk melihat apakah wilayah ini terakses dengan baik serta keberagaman pengguna serta tingkat kenyamanan dalam keseharian.

\subsubsection{Terakses}

Untuk menganalisis kategori terakses kita perlu melihat bagaimana orang mencapai wilayah ini. RPTRA Kalijodo mudah dicapai dengn menggunakan moda transportasi umum kereta, busway, angkot maupun bus wisata. Pengunjung juga bisa mencapai wilayah ini dengan menggunakan kendaraan pribadi seperti mobil dan motor. Di dalam wilayah ini disediakan parkir mobil dan motor dengan menggunakan mesin parkir dan gerbang otomatis.

\subsubsection{Keberagaman Pengguna dan Tingkat Kenyamanan}

Dengan desain yang unik, RPTRA Kalijodo menyedot banyak perhatian publik. Ketika pertama kali diresmikan, ribuan warga mendatangi RPTRA Kalijodo (Kusumawardhani, 2017). Peresmian ini juga dihadiri oleh Dubes Singapura dan mantan presiden Megawati Sukarnoputri. Adanya dinding yang bercatkan mural menambah kemeriahan acara peresmian ini. Kalijodo yang dulunya identik dengan kawasan terlarang karena pelacuran dan premanisme, kini mengubah citramya menjadi kawasan yang terbuka untuk umum, ramah terhadap lingkungan dan ruang terbuka untuk anakanak berkegiatan di dalamnya. Untuk melihat bagaimana ruang ini dalam penggunaan keseharian, maka observasi dilakukan pada hari biasa dan akhir pekan dengan melihat kategori pengguna ruang (anak-anak, remaja, dewasa, orangtua, lansia dan difabel).

\subsection{2.a Anak-anak}

Konsep awal didirikannya RPTRA adalah untuk menampung kegiatan masyarakat mulai dari bayi, kanak-kanak, remaja, dewasa, orang tua hingga manula. Dengan berlandaskan hal tersebut, maka untuk mengukur kesuksesan penciptaan ruang publik adalah melihat bagaimana ruang tersebut digunakan dalam keseharian. Dalam wilayah 
RPTRA ini bisa dilihat adanya playground yang disediakan sebagai taman bermain. Dalam kesehariannya, taman bermain ini selalu penuh dengan anak-anak.

Hasil wawancara dengan menggunakan kuesioner terhadap pengunjung anak anak menunjukan bahwa $95 \%$ responden anak-anak yang datang ke RPTRA Kalijodo memang bertujuan untuk bermain dan sisanya untuk belajar di perpustakaan. Meskipun wilayah ini terbagi atas RPTRA dan RTH, dalam keseharian, pengunjung tidak membedakan wilayah ini menjadi dua bagian. Mereka umumnya menganggap keseluruhan wilayah ini adalah RPTRA Kalijodo. Dengan adanya fasilitas ruang bermain anak seperti futsal, playground, trek sepeda, sepatu roda, ataupun skateboard, memberikan kesempatan pada anak-anak untuk bebas beraktifitas di ruang ini.

Selain bermain, anak - anak bisa mendapatkan manfaat lain ketika berada pada RPTRA Kalijodo, yaitu dengan membaca pada perpustakaan umum. Menurut penuturan pengurus RPTRA Kalijodo, setiap harinya perpustakaan selalu dibuka untuk dikunjungi anak -anak yang ingin membaca buku yang disediakan. Bahkan ada beberapa anak yang memang rutin membaca pada perpustakaan RPTRA Kalijodo ini (Interview1, 2017). Berdasarkan hasil observasi, perpustakaan tersebut memang selalu dibuka setiap harinya, akan tetapi hanya terlihat beberapa anak pada jam - jam tertentu saja yang beraktifitas dalam perpustakaan tersebut.

Hasil kuesioner menunjukkan bahwa area bermain skateboard menjadi wahana favorit pengunjung (Gambar 9). Umumnya anak-anak akan belajar dari satu sama lain dan berkenalan dengan anak-anak lain dari berbagai wilayah. Menurut salah satu pengguna, awalnya sebelum ada RPTRA ia jarang bermain diluar rumah karena kesulitan mendapatkan ruang tempat ia bermain dengan layak. Lalu setelah ada RPTRA Kalijodo, kini hampir setiap sore hari ia bermain sepatu roda pada RPTRA Kalijodo ditemani ayahnya. Biasanya saat bermain, ia bisa menghabiskan waktu 2 - 3 jam di RPTRA Kalijodo. Kini ia mulai mahir bermain sepatu roda, padahal ia baru mulai belajar sepatu roda ketika RPTRA Kalijodo dibangun (Interview2, 2017). Pada kawasan ini, anak-anak bebas berkegiatan tanpa harus diawasi oleh orang tua. Keamanan wilayah ini juga dipengaruhi oleh adanya CCTV yang diawasi oleh pengelola RPTRA.

Kegiatan anak-anak secara konsisten terjadi pada wilayah RPTRA dan RTH pada hari kerja (weekday). Kegiatan yang dilakukan anak - anak yaitu bermain futsal, bermain pada playground, dan beberapa membaca di perpustakaan. Menjelang sore hingga malam, di RPTRA Kalijodo bagian selatan mulai sepi aktifitas, sehingga pengurus RPTRA mulai memadamkan lampu pada bagian tersebut. Pada saat sore dan malam hari di hari kerja, anak - anak lebih banyak berkegiatan pada RTH bagian utara. Kegiatan anak - anak dimalam hari banyak bermain pada area skateboard dan trek sepeda. Selain bermain di area tersebut, banyak juga anak - anak bermain di area komersil yang terdapat disekitar RTH. Hal ini karena pada daerah komersil tersebut banyak menyediakan permainan anak seperti odong - odong atau becak mini.

Pada akhir pekan dan hari libur, jumlah anak-anak yang beraktifitas di wilayah ini meningkat signifikan. Pengunjung mendatangi wilayah ini dari pagi hingga malam dan RPTRA serta RTH menjadi sebuah simbol ruang publik baru bagi kota Jakarta.

\subsection{2.b. Remaja}

Analisis pengguna RPTRA Kalijodo selanjutnya adalah kelompok remaja. Melalui RPTRA Kalijodo ini para remaja mendapat ruang untuk menyalurkan kebutuhan sosialnya yang bermanfaat bagi mereka serta meminimalisir timbulnya kegiatan negatif pada remaja akibat tidak adanya ruang yang positif bagi mereka. Berdasarkan hasil wawancara dan observasi dengan beberapa remaja pengunjung RPTRA Kalijodo, biasanya para remaja ini datang bersama teman, pasangan ataupun orang tuanya dan 
dengan berbagai alasan. Hasil kuesioner menunjukkan bahwa $80 \%$ remaja datang karena ingin menikmati fasilitas olahraga dan tempat bermain seperti skate park, jogging track, sisa 20\% remaja yang datang karena ingin menikmati suasana RPTRA Kalijodo atau sekedar berfoto pada RPTRA Kalijodo ini.

Hasil wawancara dengan salah satu remaja, dia sudah beberapa kali datang ke RPTRA Kalijodo bersama teman - temannya, untuk menyalurkan hobi fotografinya. Baginya obyek fotografi di RPTRA Kalijodo sangat bagus, karena dapat memperlihatkan bagaimana kehidupan sosial masyarakat serta sangat "kekinian". Meski ia tahu seperti apa Kalijodo dahulu, namun menurutnya, RPTRA Kalijodo saat ini sudah berubah drastis dan tempat yang sangat cocok untuk anak muda berkegiatan. Tidak jarang, hasil fotonya ia unggah di sosial media, karena ia merasa bangga berkegiatan dan menghasilkan sebuah karya di ruang publik RPTRA Kalijodo ini (Interview3, 2017).

Selain Randy, ada juga Krisna, yang datang ke RPTRA Kalijodo dengan pasangannya. Ia tinggal di Bogor, dan bekerja di Jakarta. Di sela - sela kesibukan kerjanya, ia menyempatkan datang ke RPTRA Kalijodo bersama kekasihnya menggunakan KRL dan TransFeeder. Baginya RPTRA Kalijodo merupakan tempat yang sangat tepat untuknya dapat melepas penat dari perkerjaan. Kemudian, hal penting lainnya memilih untuk berkegiatan di RPTRA Kalijodo juga karena ia tidak perlu mengeluarkan biaya sedikitpun selama berkegiatan dalam RPTRA Kalijodo. Jika ingin makan, maka banyak jajanan yang dapat mereka pilih yang tentunya ramah untuk kantong karyawan muda. Meski tidak mengetahui bagaimana RPTRA Kalijodo sebelumnya, namun ia sama sekali memiliki pandangan negatif selama berkegiatan di RPTRA Kalijodo ini (Interview3, 2017).

Selain itu RPTRA Kalijodo juga dijadikan wadah bagi para remaja melakukan kegiatan sosial yang tentunya bermanfaat bagi masyarakat seperti kegiatan mengajar membaca dan mendongeng untuk pengunjung anak - anak yang kerap dilakukan di ruang serba guna atau seminar - seminar seperti penyuluhan narkoba yang kerap dilakukan di paviliun. Beragam kegiatan sosial tersebut dapat mereka lakukan dengan mudah dan tanpa harus menyewa tempat. Dengan hanya mendaftar ke pengurus dan menyesuaikan dengan jadwal yang ada, maka setiap ruang baik itu ruang serbaguna atau ruang lain yang memungkinkan pada RPTRA Kalijodo ini dapat digunakan untuk kegiatan yang bersifat sosial.

Para remaja ini lebih banyak berkegiatan pada RPTRA Kalijodo di wilayah Jakarta Utara. Hal ini karena fasilitas RPTRA Kalijodo di wilayah Jakarta Utara lebih mendukung untuk kegiatan para remaja. Saat pagi dan siang hari diwaktu weekdays jumlah remaja yang berkegiatan di RPTRA Kalijodo lebih sedikit dibandingkan jumlah anak - anak (Gambar 2). Hal ini karena para remaja biasanya memiliki kesibukan seperti sekolah pada pagi dan siang hari. Menjelang sore hari, barulah para remaja ini datang. Kegiatan para remaja ini banyak dilakukan pada area skateboard dan trek sepeda. Selain itu banyak juga para remaja yang berfoto - foto pada dinding mural ataupun sekedar duduk bersantai di paviliun, amphitheater ataupun RTH. Para remaja ini bisa berkegiatan di RPTRA Kalijodo hingga jam 10 malam, sedangkan saat akhir pekan, hingga jam 12 malam. Selama masih banyak yang beraktifitas pada RPTRA Kalijodo, maka lampu penerangan tidak akan dimatikan oleh pengurus. Di waktu akhir pekan, kegiatan remaja di RPTRA Kalijodo ini sudah mulai ramai dari pagi dan siang hari (Gambar 3). Banyak dari para remaja yang berolah raga pada jogging track. Menjelang malam hari kegiatan yang dilakukan sama seperti di waktu weekday. Jumlah pengunjung diidentifikasi oleh perbedaan warna yang menunjukkan tingkat keramaian pengguna. Merah menunjukkan pada titik tersebut terdapat kurang lebih 50 orang pengunjung, oranye menunjukkah kurang lebih 30-50 orang, kuning menunjukkan intensitas jumlah pengunjung sedang 
yaitu 10-30 orang, dan abu-abu menunjukkan intensitas pengunjung sepi yaitu kurang dari 10 orang.

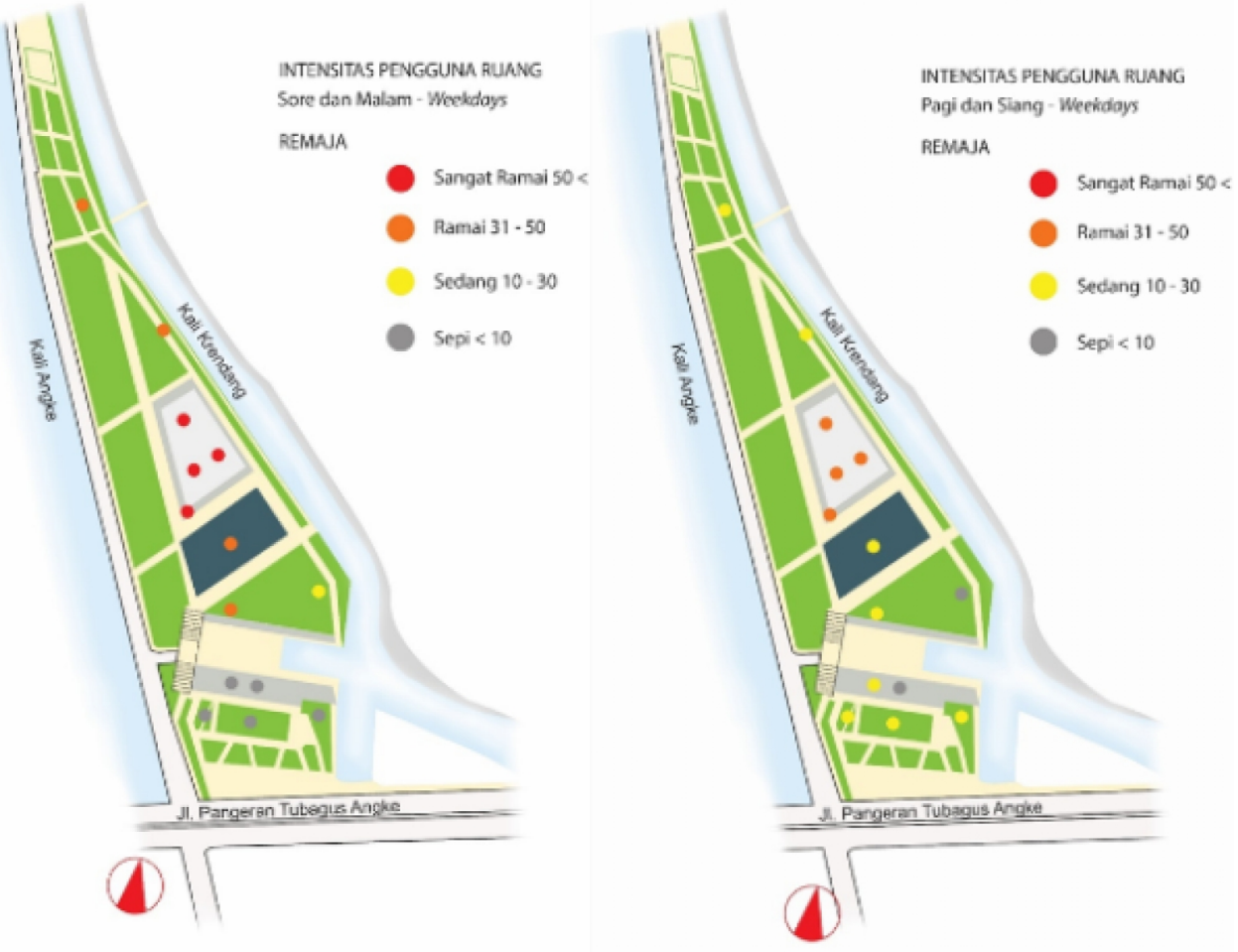

Gambar 3: Intensitas pengguna remaja pada hari kerja (Weekday)
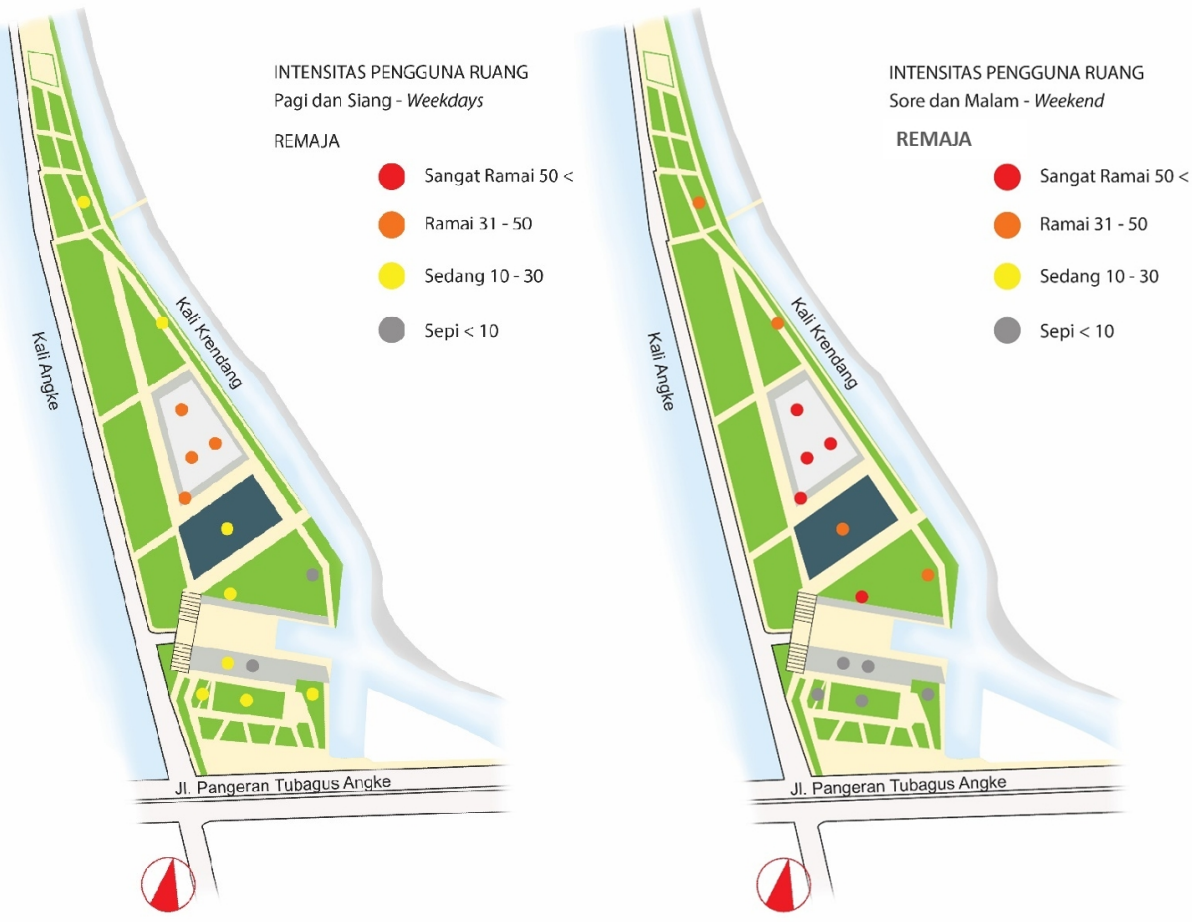

Gambar 4 Intensitas pengguna remaja pada akhir pekan/libur (Weekend)

\subsection{2.c. Orang tua}

Para orang tua juga berkesempatan melakukan kegiatan pada RPTRA Kalijodo. Berdasarkan hasil pengisian kuesioner, banyak orang tua yang berkunjung ke RPTRA 
Kalijodo untuk mengawasi anaknya bermain. Namun adapula yang sengaja datang untuk menikmati suasana dan berbagai fasilitas yang ada pada RPTRA Kalijodo seperti taman, tempat duduk, jajaran para pedagang disepanjang RTH Kalijodo ini. Kegiatan ini tentunya dijadikanya sebagai tempat untuk melepas penat dari kesibukannya sehari - hari dan bercengkerama bersama kerabat dan keluarganya masing - masing.

Selain itu sebagai ruang publik, RPTRA Kalijodo menjadi tempat favorit para orang tua untuk melakukan berbagai kegiatan. Dari hasil observasi, penulis mengetahui bahwa ada beberapa kegiatan yang dilakukan orang dewasa pada RPTRA Kalijodo ini. Ada yang datang untuk berolahraga pada jogging trek atau membawa hewan peliharaannya keluar, ada yang memanfaatkan ruang publik untuk tempat mereka melaksanakan beragam kegiatan rutin seperti para ibu - ibu yang berlatih kosidah, pengajian, penyuluhan kanker payudara. Lahan yang luas juga dimanfaatkan para orang tua sebagai tempat melakukan kegiatan masal seperti senam aerobik. Berbagai kegiatan ini dapat dilakukan pada RPTRA Kalijodo dengan terlebih dahulu mendaftarkannya kepada pengurus RPTRA terlebih dahulu (Interview4, 2017).

Para orang tua yang berkegiatan pada RPTRA Kalijodo ini lebih banyak berfokus pada pada tempat - tempat yang memiliki tempat duduk. Hal ini karena para orang dewasa datang bukan untuk bermain, namun sekedar menikmati pemandangan. Banyak juga para orang tua yang membeli barang dagangan pedangan. Selain itu jika ada acara acara khusus seperti kegiatan di ruang serbaguna ataupun pada paviliun. Hal ini karena banyak dari ruang yang ada pada RPTRA Kalijodo bersifat fleksibel.

\subsection{2.d. Lansia dan Difabel}

Pada RPTRA Kalijodo ini, para lansia dan kaum difabel juga diberikan fasilitas untuk dapat menggunakan ruang - ruang yang ada pada RPTRA Kalijodo ini. Hal ini dapat dijadikan alternatif disaat para lansia dan kaum difabel kesulitan mencari ruang yang dapat mengakomodir keterbatasan yang mereka miliki. Setiap ruang yang ada pada RPTRA Kalijodo dapat diakses menggunakan kursi roda karena sudah difasilitasi menggunakan ramp sehingga pengguna kursi roda dapat mengjangkau setiap ruang yang ada. Selain ramp, fasilitas pendukung lainnya yang yang mendukung kegiatan para lansia dan kaum difabel seperti taman refleksi dan toilet khusus difabel. Dengan adanya berbagai fasilitas tersebut sangat membantu bagi para lansia dan kaum difabel dapat mendapatkan hak yang sama di ruang publik.

Para lansia dan kaum difabel biasanya datang bersama keluarganya masing masing. Area kegiatan mereka banyak dilakukan di pavilion karena areanya yang luas sehingga saling berdesakan dan lebih leluasa terutama bagi yang menggunakan kursi roda. Selain itu banyak juga yang berjalan bersama keluarganya dia area pedagang. Banyak juga yang memanfaatkan fasilitas trek releksi yang tersebar di beberapa titik.

\subsection{Runtuhnya rezim Ahok dan kembali menggeliatnya praktek perdagangan liar dan prostitusi}

Seiring dengan kasus yang menimpa Ahok pada awal 2017 tentang penistaan agama, tampuk kepemimpinan Jakarta akhirnya diserahkan ke wakil gubernur Djarot. Turunnya ahok dari kursi gubernur memberikan euforia pada sekelompok masyarakat yang sebelumnya merasa tersingkir dari Kalijodo.

Kondisi RPTRA Kalijodo yang hampir setiap hari ramai di datangi masyarakat membuat para pedagang illegal tergiur untuk berjualan di kawasan RPTRA Kalijodo ini. Meski sudah terdapat fasilitas untuk berjualan di area komersial, banyak dari pedagang berjualan di luar area tersebut dan mengambil lahan jogging track. Akibatnya area jogging semakin sempit karena adanya pedagang. Alasan mereka, selain karena harus 
membayar, tidak semua pedagang dapat mendapatkan lapak yang disediakan. Meski sering kali ditegur dan diusir oleh petugas yang berada di tempat RPTRA Kalijodo, namun karena tergiur untuk berjualan di kawasan yang selalu ramai ini, banyak dari pedagang nekat tetap berjualan di lokasi tersebut (Gambar 4).

Berdasarkan hasil observasi dan wawancara, terdapat 3 jenis pedagang di RPTRA Kalijodo ini yaitu pedagang resmi, pedagang event, dan pedagang liar. Pedagang resmi adalah yang terdata oleh pemerintah dan berdagang di lokasi yang sudah ditentukan dan dikelola oleh pengelola RPTRA. Beberapa pedagang merupakan warga yang dulunya tinggal di kawasan Kalijodo ataupun tinggal disekitarnya (Interview1, 2017). Kategori pedagang event bersifat musiman menyesuaikan dengan kegiatan yang tengah berlangsung. Pedagang ini membayar sejumlah uang untuk berjualan pada periode tertentu. Lapak yang digunakan untuk berjualan di RPTRA Kalijodo ini mengambil setengah dari jalur jogging RPTRA Kalijodo (Interview5, 2017). Kategori pedagang liar merupakan pedagang tidak resmi dan tidak terdaftar. Ada yang berdagang secara berpindah - pindah, karena takut ditertibkan oleh petugas yang berjaga, tetapi ada juga yang berjualan secara menetap dan dikelola oleh salah satu oknum yang dulunya mengelola kawasan prostitusi Kalijodo. Alih-alih merangkul orang-orang yang dulunya memiliki pengaruh di kawasan Kalijodo, oknum ini direkrut secara resmi untuk turut bersama-sama mengelola RPTRA.

Berbeda dengan pedagang liar yang berpindah, pedagang liar yang menetap ini tidak ditertibkan oleh petugas. Hasil wawancara kepada pedagang liar yang ekslusif ini, keberadaan mereka dijamin oleh oknum yang memiliki pengaruh di kawasan Kalijodo dan menjadi pengurus RPTRA. Selain itu berdasarkan hasil wawancara dengan Satpol PP yang ditugaskan untuk mengawasi para pedagang liar di RPTRA Kalijodo ini mengatakan bahwa lapak pedagang yang dikelola oleh oknum tersebut tidak ditertibkan karena tidak ada perintah dari pengurus RPTRA (Interview5, 2017). Karena pedagang di wilayah ini adalah pedagang liar, maka sulit sekali untuk mengetahui sistem beroperasinya mereka dalam keseharian. Rasa curiga dan tidak suka ketika diwawancara sangat terlihat.

Selain kembalinya pedagang liar di lokasi RPTRA Kalijodo pasca lengsernya Ahok, kegiatan ilegal yang kembali hadir adalah prostitusi. Tak lama seteah Ahok lengser, gubuk-gubuk semi permanen dibawah kolong jembatan mulai dibangun dan berfungsi sebagai tempat prostitusi.

\section{Simpulan}

Perubahan makna dan fungsi ruang di RPTRA Kalijodo menunjukkan bahwa citra kota sangat bergantung pada dua dikotomi: penciptaan ruang publik oleh pemerintah sebagai simbol kota yang baru dan bagaimana ruang publik tersebut digunakan dalam keseharian. Melalui pola pikir utopian, sebuah kota umumnya diciptakan untuk mengejar mimpi dan harapan untuk menjadi lebih baik (Friedman, 2002). Namun pada kenyataanya, mimpi ini tidak selalu sejalan dengan kenyataan dalam keseharian. Ruang-ruang publik yang diciptakan oleh pemerintah seringkali digunakan secara berbeda dan jauh dari apa yang dicanangkan. Dengan menganalisis sejarah panjang kawasan Kalijodo hingga dibangunnya RPTRA dan dengan menganalisis apa yang terjadi pasca lengsernya pemerintah yang membangun ruang publik tersebut, penulis menyajikan bagaimana tumpukan makna kota saling tumpang tindih dan menggeliat untuk menunjukkan jati dirinya. Citra sebuah kota tidak lagi menjadi ajang penentuan keinginan dari atas (top down approach) melainkan sebuah kontestasi antara keinginan dari atas yang diinterpretasikan oleh keinginan dari keseharian kemasyarakatan (bottom up approach). Kawasan Kalijodo yang awalnya sangat identik dengan kawasan prostitusi berubah menjadi kawasan yang ramah akan kegiatan publik positif, dan seiring berjalan 
waktu sekarang menjadi kembali diisi dengan pedagang kaki lima dan kondisinya menjadi kurang terawat.

Hasil dari penelitian ini adalah bahwa citra sebuah kota dapat dibentuk salah satunya dengan keberadaan ruang publik. Untuk penelitian ini, wilayah RPTRA Kalijodo memiliki sejarah panjang yang unik sebelum dibangunnya RPTRA. Image pelacuran, perjudian, premanisme, pemukiman liar dan kumuh yang melekat di wilayah Kalijodo, ditumpang tindihkan oleh layer pemaknaan baru, yaitu Kalijodo sebagai ruang publik yang menampung keberagaman pengguna. Namun dibalik desain yang unik dengan melibatkan arsitek terkenal dan seniman lokal, kunci keberhasilan sebuah ruang publik juga diukur dari keberagaman pengguna, aksessibilitas dan tingkat aktifitas yang terjadi disana. Dari hasil penelitian ini menunjukkan bahwa RPTRA Kalijodo sudah menjadi ruang publik yang baik dengan menampung ragam pengguna dengan tingkat aksesibiltas yang mudah dicapai. Namun seiring dengan pergantian tampuk kepemimpinan di DKI Jakarta, pergeseran makna citra kota di RPTRA Kalijodo juga terjadi seiring dengan geliat arah pengembalian wilayah ini ke fungsi sebelumnya oleh para penguasa Kalijodo sebelumnya.

\section{Ucapan Terima Kasih}

Terima kasih penulis ucapkan kepada Universitas Pembangunan Jaya yang sudah memberikan kesempatan penelitian ini dilakukan.

\section{Daftar Pustaka}

Ardiahanni, D. (2016, Februari 15). Warga Kalijodo Pilih Pulang Kampung daripada Direlokasi ke Rusun. kompas.com.

Author. (2014). Redefining New (Postcolonial) Jakarta through the Giant Sea Wall Project. In Nezar Alsayyad (ed), IASTE Working Paper Series. UC Berkeley: Culture and Myth in Socio-Spatial Practice., Vol 256.

Aziza, K. S. (2017, Februari 22). Resmikan RPTRA Kalijodo, Ahok Klarifikasi Isu Soal Sinarmas Land. Kompas.

Boyer, C. M. (1994). The City of Collective Memory: Its Histrorical Imagery and Architectural Entertainments. Cambridge, Massachusetts: The MIT Press.

Cahya, K. D. (2016, Februari 22). Warga Kalijodo yang "Single" Akan Direlokasi ke Rusun Rawa Bebek. Kompas.com.

Francis, M. (1998). Changing Values for Public Space. Landscape Architecture.

Friedman, J. (2002). The Good City: In defence of Utopian Thinking. In J. Friedman, The Prospect of Cities (pp. 102-118). Minneapolis: University of Minnesota Press.

Gehl, J. (1987). Life Between Building (Using Public Space). London: Island Press.

Interview1. (2017, April 28). Pengurus RPTRA. (Thomas, Interviewer)

Interview2. (2017, april 28). Anak-anak. (T. Lientino, Interviewer)

Interview3. (2017, April 29). Remaja. (T. Lientino, Interviewer)

Interview4. (2017, April 28). Dewasa. (T. Lientino, Interviewer)

Interview5. (2017, Mei 04). Pedagang. (T. Lientino, Interviewer)

Kusno, A. (2000). Architecture, Urban Space, and Political Cultures in Indonesia. London and New York: Routledge.

Kusumawardhani, F. (2017, Februari 22). Antusiasme Warga di Peresmian RPTRA Kalijodo. kumparan.com.

Murti, K. (2004). Geger Kalijodo. Jakarta: Ideapress.

Permanasari, E., Nurhidayah, F., \& Nugraha, H. (2018). Metode Desain Partisipatif Sebagai Model Pembangunan 6 RPTRA DKI Jakarta. Jakarta: Universitas Pembangunan Jaya.

Pratama, A. B. (2016, Februari 17). Besok Ahok Kirim SP1 untuk Warga Kalijodo Bongkar 
Rumah. CNN Indonesia.

Putera, A. D. (2016, Maret 01). Penambahan RTH Tak Harus Membongkar Wilayah Berpenghuni. Kompas.

Rossi, A. (1986). The Architecture of the City. US: The MIT Press.

Saidi, R. (2016, Februari 20). Berawal dari Peh Cun (wawancara dengan liputan6). Retrieved from Viva.co.id: http://sorot.news.viva.co.id/news/read/738159kalijodo-selayang-pandang

Silado, R. (1999, Februari). Ca-Bau-Kan: Hanya Sebuah Dosa. Indonesia.

Suardana, I. K. (2000). Kehidupan Pelacur di Pemukiman Kumuh Liar Kalijodo RW 05 Kelurahan Pejagalan Kecamatan Penjaringan Jakarta Utara. Jakarta: Universitas Indonesia.

Sumantri, A. (2016, Februari 13). Selain Prostitusi, ini alasan Ahok Gusur Kalijodo. Metrotvnews.com.

Syurkani, P. (2016, Februari 28). Pembersihan Kalijodo Berlangsung Tiga Hari. Media Indonesia.

Tionghoa. (2015, 06 20). Festival Perayaan Duan Wu Jie (Peh Cun / Bak Cang). Retrieved from Tionghoa (Budaya, Tradisi, Sejarah \& Adat Tionghoa): https://www.tionghoa.com/festival-perayaan-duan-wu-jie-peh-cun-bak-cang/

Vale, L. (1992). Architecture, Power and National Identity. London: Yale University Press.

Yuliawati. (2016, Februari 17). Remy Sylado Tolak Penggusuran Kalijodo. CNN Indonesia. 